\title{
VARIETIES OF ONTOLOGICAL ARGUMENT ${ }^{1}$
}

\author{
HOWARD ROBINSON
}

Central European University, Budapest

\begin{abstract}
I consider what I hope are increasingly sophisticated versions of ontological argument, beginning from simple definitional forms, through three versions to be found in Anselm, with their recent interpretations by Malcolm, Plantinga, Klima and Lowe. I try to show why none of these work by investigating both the different senses of necessary existence and the conditions under which logically necessary existence can be brought to bear. Although none of these arguments work, I think that they lead to interesting reflections on the nature of definition, on the conditions for possessing the property of necessary existence and point towards a different, neo-Platonic ground for God's meeting the criteria for being logically necessary.
\end{abstract}

\footnotetext{
${ }^{1}$ This paper has a long history. The idea that the simpler versions of the ontological argument fail, not because 'existence is not a predicate', but because of a misunderstanding of the nature of definition, began life for me in a graduate paper written for Basil Mitchell in 1969. Much of the rest of the paper was developed for a Jan Hus Society sponsored 'flying university' talk in the suburbs of Prague in 1986, chaired by Petr Rezek: this was further modified for a completely above board talk in Budapest in 1988. This latter version was published in the final edition of the journal Annales in Budapest in 1992. This fascicule was edited by Istvan Bodnar, Gabor Boros and Kornel Steiger - three philosophers who have done heroic work in developing the history of philosophy in Hungary during the final years of communism and into the democratic era. Various versions of the paper have also been presented at meetings in Oxford and Liverpool and I have recently benefited from discussion with Brian Davies, O.P. Because I would like the piece to be available to a wider readership than the obscure and extinct Annales could make it, and because I wish to bring that article up to date, I present this revised version here. I am very grateful to Fordham University for allowing me to be a visiting scholar during the period when I was rewriting the article.
} 


\section{INTRODUCTION}

At least two important monographs on the ontological argument (OA) have appeared in the last forty years. One is Jonathan Barnes's pellucid (1972), the other Graham Oppy's wide ranging (1995). ${ }^{2}$ Barnes was unfortunate because his book arrived just before Plantinga (1974) gave new life to the issue with his modal version of the argument. ${ }^{3}$ Oppy of course, covers this, but it seems to me that there is still room for an article-length opinionated survey of the various versions of the argument, including those more recent than Oppy. I shall try to provide this, and, although my conclusions will be, with reservations, negative, I believe they will point usefully to other related issues.

\section{THE ELEMENTARY OR ‘SCHOOLBOY’ VERSION OF THE ARGUMENT}

The OA is associated with a variety of important philosophers, the most important being Anselm and Descartes. Both these philosophers stated the argument in more than one significantly different way. There is, however, what one may characterize as the popular version of the argument. This is roughly equivalent to one of the versions generally believed to be in Descartes and Leibniz, and fundamentally similar to St. Thomas's construal of Anselm. It is probably this version of the argument which is nearest to what the average undergraduate understands by 'the ontological argument.' This version of the argument can be expressed as follows:

A (1) God is, by definition, the most perfect being conceivable.

(2) Existence is a perfection: that is to say, to be perfect one must exist in reality (and not just in the understanding, or not at all). Therefore,

(3) God, by definition, exists in reality.

The Kantian tradition of objections to the argument finds fault with the second premise on the grounds that existence, not being an attribute (because 'exists' is not a predicate) cannot be a component in perfection. An older tradition of resistance to the argument, represented by St Thomas

\footnotetext{
${ }^{2}$ Jonathan Barnes, The Ontological Argument (London: Macmillan, 1972); Graham Oppy, Ontological Arguments and Belief in God (Cambridge: Cambridge University Press, 1995).

${ }^{3}$ Alvin Plantinga, The Nature of Necessity (Oxford: Clarendon Press, 1974).
} 
and Caterus, thought it an abuse of what can be achieved from the mere definition or content of a word or concept. St Thomas, I think, does not manage to do better than merely assert that the transition from meaning to reality cannot be made:

Yet granted that everyone understands that by this word 'God' is signified something than which nothing greater can be thought, nevertheless, it does not therefore follow that he understands that what the word signifies, exists actually, but only that it exists mentally. ${ }^{4}$

Caterus, in glossing St Thomas, improves on him saying:

Though it be conceded that an entity of the highest perfection implies its existence by its very name, yet it does not follow that very existence is anything actual in the real world, but merely that the concept of existence is inseparably united with the concept of highest being. (My italics. $)^{5}$

Nevertheless, not even Caterus' objection makes entirely explicit what is wrong with the argument in the form that I have stated it. That argument is prima facie valid, and the suggestion is that something is wrong with the first premise. Essentially the mistake consists in the use of the word 'God' as a referring expression in (1), for then (1) will be true only if 'God' - its subject term - does refer. So (1) is true (and the argument possibly sound) only if 'God' refers - that is, only if God exists. So the existence of God is presupposed, not demonstrated, by the argument. ${ }^{6}$ One possible response to this objection is to restate the argument mentioning, not using, 'God': if this could be done whilst still producing a valid argument it may be sound.

B (1) 'God' means, by definition, the most perfect being conceivable.

(2) Existence is a perfection: that is, to be perfect something must exist in reality (and not just in the mind or not at all).

Therefore,

(3) 'God' means, by definition, the being that is the most perfect being conceivable and which, therefore, exists in reality.

Therefore,

(4) By definition the being called 'God' which is the most perfect being conceivable, exists in reality.

${ }^{4}$ Summa Theologica, 1a qu.2 ad.1. Also quoted in Alvin Plantinga (ed.) The Ontological Argument (London: Macmillan, 1968), p. 29.

${ }^{5}$ Quoted in Plantinga (1968), p. 37.

${ }^{6}$ See Barnes, The Ontological Argument, pp. 67ff. 
This is, in a way, an extremely difficult argument to refute directly. A first thought might be that (1) is not of a proper form for a definition for certain inverted commas are missing and that it ought to read:

(1') 'God' means, by definition, 'the most perfect being conceivable'.

(3) would then become

(3') 'God' means, by definition 'the being that is the most perfect conceivable and which exists in reality'.

From (3') one could not move to the referring use of 'the' in "the being called 'God'" which is necessary for (4), for reference is made in (3') only to expressions. This objection is on the right lines, but is not quite right because one is not obliged, when giving a definition, to place both definiens and definiendum in inverted commas; in the definiens one is not referring only to an expression. It is perfectly proper, for example, to say that "'Table' means (or 'signifies'), by definition, a raised surface able to sustain the weight of household objects". Nor is this possible in the case of 'table' only because it is a common noun which can have many instances. It is possible to do the same for a definite description: for example: “The expression 'the Queen of England' means (or 'signifies') the female sovereign or consort of England".

It was because of the difficulty of producing a knock-down objection to this sort of argument that its opponents resorted to the indirect method of reductio ad absurdum. This is the point of Gaunilo's 'perfect island' and Caterus's 'existent lion', both of which have existence built into their definition and so must, if the corresponding version of the ontological argument is sound, exist by definition. The rationale of this strategy is that if the argument is sound then one can manufacture any concept which includes existence and thereby prove that that sort of thing exists, which is absurd.

This does not, however, tell us what is wrong with the argument. The error could lie in deeming existence to be a perfection or a predicate, as Kant claimed, but the nature of the above considerations points to its lying in a misconception about the nature of definition.

What exactly is this misconception?

The reason why it is not possible to show that something exists simply by exhibiting its definition is that definitions are conditionals. The definition of 'table' given above could be rewritten as: 
Necessarily, something is a table if and only if it possesses a raised surface able to sustain the weight of household objects.

For any given element in the definition the conditional is explicit:

Necessarily, if something is a table then it has a raised surface. Applying these forms to the definition of 'God', we have:

Necessarily, something is God if and only if it is the most perfect being conceivable

and

Necessarily if something is God then it exists.

This latter proposition is interesting for its banality. Once the conditional nature of definitions is grasped, the argument comes out as follows:

C (1) Necessarily, if there is something which is God, then it is the most perfect being conceivable.

(2) Existence is a perfection: that is, to be perfect something must exist in reality (and not just in the mind, or not at all).

Therefore,

(3) Necessarily, if there is something which is god, then it exists in reality.

One could substitute any noun F for 'God' in (3) and the sentence would remain true, unless the $\mathrm{F}$ in question was of a mythical or fictional entity. Except in these latter cases, existing is a necessary condition for being anything and hence can harmlessly be included in the definition of anything - indeed it goes without saying that existence enters into the definition of any $\mathrm{F}$, if definition involves giving necessary and sufficient conditions for being $\mathrm{F}$ : something could not be an $\mathrm{F}$ without existing. These last remarks are not meant to be a weighty contribution to the question of whether 'exists' is a predicate. Rather the point is that even if we follow the superficial grammatical facts and treat it as a predicate, it enters harmlessly into definitions, once the conditional nature of definition is perceived. The most easily intelligible fault in the popular version of the ontological argument has nothing to do with whether 'exists' is a logical predicate.

\section{DESCARTES’S ARGUMENT FROM 'ESSENCE', NOT DEFINITION}

The popular version of the argument is not, however, the only one. Indeed, the view that the argument rests on the definition of the word 
'God' is confined almost exclusively to its opponents. Descartes insisted, against Caterus, that his argument rested, not on the definition of the word 'God' but on the 'immutable nature' or 'essence' of God. He argues as follows:

D (1) Anything belonging to the true immutable nature, essence or form of a thing can be truly affirmed of it.

(2) To exist belongs to God's immutable nature.

Therefore,

(3) Existence can be truly affirmed of God - i.e. God exists.

The soundness of this argument depends on what the expressions 'immutable nature', 'essence', etc. are taken as referring to. If God's 'immutable nature' is a facet or feature of God Himself, then reference to it is possible only if God exists, and the argument is no better than the first version that we considered. If, on the other hand, the 'immutable nature' or 'essence' is some sort of abstract object, the existence of which does not depend directly on God's existence, then it appears to be no different from the concept of God. To learn that the concept of God includes existence is no more interesting than discovering that the definition of 'God' includes existence: like the latter, it means only that for something to be God it must exist. If it does not mean this harmless conditional, Descartes would be saying that when he thinks of the concept of God he can see that this concept must of its very nature be instantiated. But interpretation of the argument in this way empties it of its argumentative force. The purpose of the ontological argument is to make clear why this concept must be instantiated: the arguments from definition at least made this clear; it is, they say, because existence is part of the definition of the concept. Just to say that this concept must be instantiated without explanation is not an argument: to say that it must be instantiated because existence to part of the concept is to fall back on to the conditional form: if something is to instantiate the concept 'God' then it must exist.

\section{PROSLOGION II}

It seems that refutation of the Cartesian forms of the argument is independent of whether 'existence is a predicate'.

The same seems to be the case for at least the first of the three Anselmian forms of the argument. In Proslogion II, Anselm says the following:

And so Lord ... we believe that thou art a being than which nothing greater can be conceived ... Even the fool is convinced that something exists in the 
understanding, at least, than which nothing greater can be conceived. For, when he hears of this, he understands it. And whatever is understood, exists in the understanding. And assuredly, that, than which nothing greater can be conceived, cannot exist in the understanding alone. For, suppose it exists in the understanding alone: then it can be conceived to exist in reality; which is greater. Therefore, if that, than which nothing greater can be conceived, exists in the understanding alone, the very being, than which nothing greater can be conceived is one, than which a greater can be conceived. But obviously this is impossible. Hence, there is no doubt that there exists a being, than which nothing greater can be conceived, and it exists both in the understanding and in reality. ${ }^{7}$

At first sight one might be tempted to treat this argument as essentially similar to the popular version with which we began. It would then run as follows:

E (1) God is greater than anything else conceivable.

(2) It is greater to exist in reality than in the understanding alone. Therefore,

(3) God exists in reality, not in the understanding alone.

This argument differs only in trivial verbal ways from the original popular version of the argument that we considered initially; 'God' is being used as a referring expression and hence the question is begged. But this does not do full justice to the oddity of Anselm's argument. It can be restated in a way which mentions rather than uses 'God' and which accommodates the conditionality of definition, yet which leads validly to the desired conclusion.

F (1) If anything is God then it is greater than anything else conceivable.

(2) God exists in the understanding.

Therefore,

(3) God exists - that is, something is God. ((2), a fortiori)

Therefore,

(4) God is greater than anything else conceivable. ((1), (3) MP)

(5) It is greater to exist in reality than in the understanding alone.

${ }^{7}$ This is an abridgment of chapter 2 of the Proslogion. It is in Plantinga (1968), pp. 3-4. An easily available edition of Anselm alone is St Anselm: Basic Writings, translated S. N. Deane, with an introduction by Charles Hartshorne (La Salle, IL: Open court, 1962), pp. 53-4. 


\section{Therefore,}

(6) God exists in reality, not in the understanding alone.

The trick is worked in the full version of the argument by deeming God's existence in the understanding to be a real mode of His existing. This enables us to overcome the conditionality of the definition in (1). The line of argument in (1) to (3) is not explicit in Anselm's text, but it's conclusion is essential to his argument. The reductio conclusion that, if God existed only in the mind then He would both be and not be the greatest being conceivable follows only if what is in the mind is God. There is no contradiction if what is in the mind is simply the idea of God, for there is no reason to say that that is the greatest being - it is just the idea of the greatest being. Although this view of existence in the understanding is plainly in Anselm's text, it is also plainly false. Even contemporaries pointed out to Anselm that 'x exists in S's understanding' was merely a way of saying 'S has an idea of $\mathrm{x}$ '. Is there any way of making Anselm's move less of a simple howler?

The move from (2) to (3) can, however, be made less bizarre than it seems at first sight if one imputes to him a certain theory of concepts. Concepts are somewhat mysterious entities and it would not be entirely alien to the classical approach to thought to say that the concept of $\mathrm{x}$ is literally to be explained as the existence-in-the-mind of $x$ itself. Such a theory could be compared to the realist theory-of-appearing approach to perception. According to the latter, when I see an object looking red that object is appearing redly to me: that is, the object itself confronts my sense under a particular mode of appearing. Similarly, in thought objects take on, not a sensory form, but an intellectual one - an esse intentionale and so constitute the content of those mental acts which concern them.

There are two grounds for doubting whether Anselm could have held such a theory. First, it may be anachronistic to ascribe such an Aristotelian-seeming theory to Anselm. Second, it involves allowing that a particular object enters the intellect, whereas the intellect deals only with forms. This modification might, however, help our understanding of the argument, and the manner of its rejection by Gaunilo and St Thomas. In the case of normal objects, it is their form which enters the intellect where it is 'thought universally' - that is, deprived of the matter which creates its individuality in the object itself. Such objects, therefore, do not really exist in the intellect, but only their forms. But for God the case, it could be argued, is different. God's essence - His form - and 
His existence are identical, according to mediaeval thought. Therefore, if God enters our thoughts in the same way as other objects, by His form entering the intellect, His existence would thereby also become the direct object of the intellect, and the very being of God would be grasped by the mind in a way comparable to that in which one might hold that an abstract object (e.g. a universal) is directly apprehended, leaving no gap between the mental object and the thing itself. That such a theory of thought is relevant to the argument is suggested by Aquinas' otherwise puzzling development of his objections. He says that a proposition can be self-evident in either of two ways: either in itself, or in itself and to us.

A thing can be self-evident in either of two ways; on the one hand, selfevident in itself, though not to us; on the other, self-evident in itself, and to us. A proposition is self-evident because the predicate is included in the essence of the subject, as 'Man is an animal' for animal is contained in the essence of man. If, therefore, the essence of the predicate and subject be known to all, the proposition will be self-evident to all; as is clear with regard to the first principles of demonstration, the terms of which are common things that no-one is ignorant of, such as being and non-being, whole and part, and suchlike. If, however, there are some to whom the essence of the predicate and subject is unknown, the proposition will be self-evident in itself, but not to those who do not know the meaning of the predicate and subject of the proposition. ... Therefore, I say that this proposition, 'God exists', of itself is selfevident, for the predicate is the same as the subject; because God is His own existence as will be hereafter shown (1aQ. III, a. 4). Now because we do not know the essence of God, the proposition is not self-evident to us; but needs to be demonstrated by things that are more known to us, though less known in their nature - namely, by effects. ${ }^{8}$

In this passage Aquinas concedes that if we knew enough of God's nature then we would see that 'God exists' expresses an analytic truth, because $\mathrm{He}$ - or His essence - is not distinct from His existence. This prompts the reply that we do, if we have read and believed Summa Theologica 1a.Q.III, A.4, know that God's existence is identical with His essence, and we know, therefore, that the predicate of 'God exists' is contained in the subject and hence that the ontological argument is sound. But this objection to Aquinas misses the point. Although we may be convinced that the proposition that 'God's essence is identical with His existence'

\footnotetext{
${ }^{8}$ Summa Theologica, 1a qu.2 ad.3. Quoted in Plantinga (1968), pp. 29-30.
} 
is true, we can never apprehend its truth simply by contemplating its subject and predicate, as we can with 'man is an animal' or 'four is twice two', because the form of its subject is beyond our intellectual grasp. We are obliged, therefore, to approach its truth indirectly. The words can never convey directly to us the full reality of the truth they express, and there is no contradiction of what is directly before our minds in doubting its truth and hence in doubting the truth of 'God exists'.

The Thomist position can be expressed as follows. Philosophy can show that the concept of a being whose existence is identical with its essence is a coherent one and it can bring a posteriori arguments to show that there is such a being; but the human intellect is incapable of apprehending a priori that there is such a being because it cannot think the divine form, which would be required to apprehend a priori its inseparability from existence. Anselm's error is to think that an understanding of the words is equivalent to grasping the forms that lie behind them, and hence of thinking that the Divine Form, which is inseparable from the Divine existence, exists in his own mind.

\section{AN ALTERNATIVE STRATEGY FOR MAKING REFERENCE TO GOD NON-QUESTION-BEGGING?}

It might seem that Gyula Klima ${ }^{9}$ has a strategy for circumventing most of my arguments in section 1-4 above. He maintains (rightly in my view) that reference is an intentional idiom and so one can refer to something and attribute it properties without committing oneself to its existence. One can talk about, and hence refer to, the Abominable Snowman, the Fountain of Youth, or God, irrespective of whether they exist. So the referential use of 'God' in 'God is the greatest being conceivable' is legitimate and neither requires rewriting in conditional form ('if something is God then it is the greatest being conceivable') nor does it assume His existence; as the idiom is intentional, you can then say God is the greatest being conceivable referentially without begging the question of His existence. This is, I believe, unobjectionable so far. The question is whether this legitimizes Anselm's argument. Klima believes that it does and argues as follows, using 'thought object' as his term for an intentional object

${ }^{9}$ Gyula Klima, 'St Anselm's Proof: a Problem of Reference, Intentional Identity and Mutual Understanding', in Medieval Philosophy and Modern Times, ed. G. Hintikka (Dordrecht: Kluwer, 2000), pp. 69-88. 
By the meaning of the term,

G (1) God is the thought object than which no thought object can be thought to be greater.

Now suppose that

(2) God is only in the intellect (i.e. God is thought of, but does not exist).

But certainly

(3) any thought object that can be thought to exist in reality can be thought to be greater than any thought object that is only in the intellect.

And it cannot be doubted that

(4) God can be thought to exist in reality.

Therefore,

(5) Some thought object can be thought to be greater than the thought object than which no thought object can be thought to be greater $[1,2,3,4]$

which is a contradiction, whence we have to abandon our supposition that God is only in the intellect, so he has to exist in reality, too.

(3) is the crucial line. It says, in effect, that God qua intentional object, or intentionally inexistent, would not be the greatest being conceivable, as any real being one thought of would be greater. But this employment of intentional reference is surely an abuse. (3) cannot be correct because most thought objects that exist only in the intellect can be and often are thought to exist in reality, but they are not thereby rendered greater than themselves. For example, maybe the Abominable Snowman exists only in the intellect, but can be (because it is) thought to exist in reality by those who believe in it. In fact anything not explicitly contradictory, fictional or mythological can be thought to exist in reality, whether it does or not. So God, even if He does not exist, is thought of as existing in reality. So there is not the required contrast between existing only in the intellect and being thought of as existing in reality.

I believe Klima is confusing (3) with

(3') any thought object that can be thought to exist in reality can be thought to be greater than any thought object that is thought of as only in the intellect. 
(3') applies to the explicitly contradictory, fictional or mythological. An entity qua intentional never possesses its normal properties actually. The Abominable Snowman, qua intentionally inexistent, does not make large footprints or stride through the forest: only the actual creature does these things, if it actually exists. Similarly for all its natural properties and similarly for the divine perfections: God, if He exists, is greater than anything else could conceivably be. You cannot attribute an object's defining properties to it qua intentional object, except in the conditional sense that they tell you what would have to be the case if the object were actual. The deployment of the intentionality of reference does not aid the argument and the same problems arise. None of 'God in the mind', the idea of God, or God qua intentional object are in the competition, as winners or losers, for maximal greatness.

\section{PROSLOGION III}

It is Anselm's second argument, in Proslogion III, which brings us nearest to the question of the connexion between existence and predication.

For, it is possible to conceive of a being which cannot be conceived not to exist; and this is greater than one which can be conceived not to exist. Hence, if that, than which nothing greater can be conceived, can be conceived not to exist, it is not that, than which nothing greater can be conceived. But this is an irreconcilable contradiction. There is, then, so truly a being than which nothing greater can be conceived to exist, that it cannot even be conceived not to exist; and this being thou art, O Lord, our God.

Modern commentators have argued that this argument is different from that in Proslogion II because it attributes by definition to God the property of necessary existence, rather than the property of existence. The distinction is between necessarily possessing the property of existing and possessing the property of necessarily existing: and the suggestion is that God necessarily possesses the property of existing because He possesses the property of necessarily existing. The property of necessarily existing is represented by the idea that His non-existence is inconceivable. No-one, I think, believes that Anselm was explicitly aware of employing this distinction.

From the text quoted it is easy to construct the following argument.

H (1) God is by definition the greatest being conceivable. 
(2) A being is greater if its non-existence is inconceivable than if its non-existence is conceivable.

Therefore,

(3) If God's non-existence is conceivable then He would be less great than if His non-existence were inconceivable. (Instantiation of (2).)

(4) If God's non-existence were conceivable then He would not be the greatest being conceivable.

(5) If God's non-existence were conceivable a contradiction would follow, namely, He both would and would not be the greatest being conceivable.

Therefore,

(6) God's non-existence is inconceivable.

The first thing that strikes one about this argument is that (1) is cast in the same style as the original argument, using rather than mentioning 'god' in the statement of a definition. I shall correct this soon. Next, and slightly less obvious, is that fact that (4) follows from (3) only with the assistance of a further premise.

(3a) It is conceivable that God's non-existence be inconceivable.

This is the vital assumption that logically necessary existence is the sort of property that can intelligibly be attributed to God. Restating the argument with allowance for the conditionality of definition we now have:

I (1) If something is God then it is the greatest being conceivable.

(2) Something is greater if its non-existence is inconceivable than if its non-existence is conceivable.

Therefore,

(3) If something is God, then it is greater if its non-existence is inconceivable:

(3a) It is possible that God's non-existence be inconceivable.

Therefore,

(4) If something is God and its non-existence is conceivable then it is not the greatest being conceivable.

Therefore, 
(5) If something is God and its non-existence is conceivable, then a contradiction follows, namely that it would and would not be the greatest being conceivable.

Therefore,

(6) If something is God, then its non-existence is inconceivable. Therefore,

(7) God's non-existence is inconceivable.

This argument is useless unless we can detach the consequent of (6), and, as the antecedent asserts what we are finally trying to prove, it might seem unlikely that we shall be able to do so. It appears, therefore, that this version of the argument, like the most elementary ones, is refuted by the conditionality of definition. The problem is illusory, however. The notion that the non-existence of something is inconceivable is equivalent to the claim that its existence is necessary. (6) is in fact of the form

If $\mathrm{p}$ then necessarily $\mathrm{p}$.

But it is an uncontroversial principle of modal logic that no necessary proposition can depend on a contingent proposition, but is self-standing. So from

if $\mathrm{p}$ then necessarily $\mathrm{p}$ one can conclude

necessarily $\mathrm{p}$.

So (6) is equivalent to

(6') If something is God then it [i.e. God] exists necessarily.

And from (6') we can conclude the equivalent of (7)

(7') God exists necessarily.

To make I valid we have had to augment Anselm's original two premises ((1) and (2) above) with (3a) which is a modal premise. If God's nonexistence is inconceivable, it follows, in the way we have just seen, that His existence is necessary. Such an idea includes, of course, the claim that His existence is possible. Putting this into modern jargon, we have the claim that God exists in some possible world and that if He exists in some possible world then there is a possible world in which he exists necessarily. It is by putting together these two ideas that the modern version of the argument, as I shall reconstruct it, can be built. ${ }^{10}$ We can begin with:

\footnotetext{
${ }^{10}$ The principle modern statement, which corresponds most closely to argument $\mathbf{J}$ and $\mathbf{K}$, is in Alvin Plantinga, The Nature of Necessity, pp. 214-16.
} 
J (1) If it is logically possible that one object should possess necessary existence and the other divine attributes (moral perfection, omnipotence, etc.) then there is a possible world in which there is an object which possesses those features together. (2) It is logically possible that one object should possess necessary existence and the other divine attributes.

Therefore,

(3) There is a possible world in which there is a being which possesses both necessary existence and the other divine attributes.

(4) 'Necessary existence' means existence in every possible world.

Therefore,

(5) The being which possesses necessary existence and the other divine attributes in some possible world exists in this, the actual, world.

This argument would not, even if sound, constitute a proof of the existence of an All-Perfect God in this world. It guarantees only that a being which is perfect in some possible world exists - perhaps in a much inferior form - in this one. To avoid this weakened conclusion one requires that the being possess not merely necessary existence and perfection in some world, but necessary existence and perfection in every world in which it exists: it cannot exist in an imperfect form. The argument is now altered to read as follows.

K (1) If it is logically possible that one object should possess both necessary existence, and the property of being otherwise perfect (omniscient, omnipotent, etc.) in every world in which it exists, then there is a possible world in which there is an object which possesses these features together.

(2) It is logically possible that one being should possess both necessary existence and the property of being otherwise perfect in every world in which it exists.

Therefore

(3) There is a possible world in which there is a being which possesses both necessary existence and the property of being otherwise perfect in every possible world in which it exists. 
(4) 'Necessary existence' (in the sense of the inconceivability of non-existence) means existence in every possible world.

Therefore,

(5) The being which possesses both necessary existence and the property of being perfect whenever it exists, exists and is perfect, in the actual world.

Argument $\mathbf{K}$ contains two 'transworld' notions - that is, notions that tell one not just what something is, but what it must be. The weaker transworld notion is that God never exists in an imperfect form: the stronger is the property of existing in all possible worlds. Together these are equivalent to (3a) in $\mathbf{G}$ and $\mathbf{H}$, which asserts that God - the invariably necessary perfect being - cannot be conceived to be non-existent - i.e. that there is no possible world in which He does not exist.

It is at this point in the discussion, when we are to consider whether necessary existence is a real property, that we are nearest to the Kantinspired discussion of existence and predication. We have managed to reject all the versions of the ontological argument from $\mathbf{A}$ to I without raising the question of whether 'exists' is a predicate, for the faults in the argument concerned other matters. In particular, in the classic statement of the argument in A, the fault lay with the concept of definition employed in (1) whereas Kant's attack concerned the use of 'exists' in (2) But before discussing the status of necessary existence I shall consider a final and rather different version of the argument which Anselm employs in his reply to Gaunilo. This too will throw light on the interpretation of $\mathbf{J}$ and $\mathbf{K}$.

\section{ANSELM'S THIRD ARGUMENT AND TWO CONCEPTS OF NECESSITY}

Anselm presents a third argument in the first chapter of his reply to Gaunilo. He argues:

that than which a greater is inconceivable cannot be conceived except as without a beginning. But whatever can be conceived to exist, and does not exist, can be conceived to exist through a beginning. Hence what can be conceived to exist, but does not exist, is not the being than which a greater cannot be conceived. Therefore, if such a being can be conceived to exist, necessarily it does exist. ${ }^{11}$

${ }^{11}$ Quoted in Plantinga (1968), p. 14. 
This is most simply put into a valid form as follows:

L (1) God - that than which a greater is inconceivable - cannot be conceived except as being without a beginning.

(2) Whatever can be conceived not to exist can be conceived to exist through a beginning.

Therefore,

(3) God - that than which a greater is inconceivable - cannot be conceived not to exist.

(2) is a modification of what Anselm actually says. He talks of 'what can be conceived to exist but does not exist. The argument can be put in those terms, though at greater length, but it is not necessary to do so, for Anselm's opponent is not claiming that God could exist, but does not, as his version of the premise suggests, but that, though He does, He might not have existed. Nevertheless, it is instructive to cast the argument in Anselm's form, as we shall see. It would then run:

M (1) God - that than which a greater is inconceivable - cannot be conceived except as being without a beginning.

(2) What can be conceived to exist, but does not exist, can be conceived to exist through a beginning.

Therefore,

(3) God - that than which a greater is inconceivable - cannot be conceived to exist but not exist.

Therefore,

(4) If $\mathrm{He}$ can be conceived to exist then He does exist.

The interest of this version of the argument is that it anticipates Leibniz's modification of Descartes, that God exists if His existence is possible. This is not quite Anselm's way of expressing the point: he does not consider possibility, but being conceived, and he thinks it sufficient for this that the notion be understood in a fairly superficial sense. But the conclusion of $\mathbf{L}$ is less satisfactory than $\mathbf{K}$ not merely because it is a conditional, but principally because, even if the consequent of the conditional be detached it is weaker both than the conclusion of $\mathbf{K}$ and than the conclusion Anselm seems to think he can draw. He wishes to conclude that God necessarily exists - i.e. that His non-existence is inconceivable - but this cannot be derived from $\mathbf{L}$ because what is to be negated is only that He does not exist, not that His non-existence is conceivable. 
This is the argument which Norman Malcolm thinks is sound. He reports it in the following terms.

... if you can conceive of a certain thing and this thing does not exist then if it were to exist then its non-existence would be possible. It follows, I believe, if it were to exist it would depend on other things both for coming into and continuing in existence, and also that it would have duration and not eternity. Therefore it would not be, either in reality or conception, an unlimited being, aliquid quo nihil maius cogitari possit. ${ }^{12}$

The governing idea here is that a contingent being is a dependent being. This is also the principle behind (2) in both $\mathbf{L}$ and $\mathbf{M}$. The thought is that anything which may or may not exist can also come into existence - and, presumably, pass out of existence too.

The confusion that is being made here is one made by Kant and many twentieth century philosophers, namely the mistake of confusing two senses of 'necessary being. In one sense, a necessary being is a logically necessary being, that is, one of which the proposition asserting its existence is a necessary truth, so that it exists in all possible worlds. ${ }^{13}$ The other sense of 'necessary being' is of a being which is not contingent in the sense that it is not subject to the processes of generation and decay, and which (in the case of God, at least) does not depend for its existence on anything other than itself. This latter is the sense in which, according to Aristotle and Aquinas, God is a necessary being. Now it is clearly logically contingent whether there are any beings which are not subject to the processes of generation and decay and which do not depend for their existence on anything else. These are, therefore, not the same as logically necessary beings. But it is equally plain that if a being free of the processes of generation and decay and owing its existence to nothing else were to exist, it could not have had a beginning in time, for there is no process by which it could have come to be and it could not have been created ex nihilo by anything else. It might be argued that it could have come into being, ex nihilo, without a cause - that is, by pure chance, and that the only way to rule out this possibility is to make its existence logically necessary. It is certain that the scholastics believed that nothing

${ }^{12}$ Plantinga (1968), p. 145.

${ }_{13}$ This distinction was first brought clearly to the attention of modern philosophers by Patterson Brown, 'St Thomas's doctrine of necessary being', Philosophical Review, vol. LXXIII (1964), pp. 76-90. Reprinted in Aquinas: A Collection of Critical Essays, ed. Anthony Kenny (New York: Doubleday, 1964), pp. 157-74. 
could come to be ex nihilo except by a creative act, but one may reject this principle (though I doubt whether Anselm would have rejected it). The thought would be that to come into existence is to receive existence from elsewhere and therefore to breach one of the conditions for being the sort of necessary being that God is said to be. It might be doubted, however, whether a being that just pops into existence receives its being from anywhere. Nevertheless, such an event could not be part of any naturally intelligible or explicable process and such a being could not be generated: the possibility of its coming randomly into existence is not something that belongs to it as an expression of the kind of thing that it is. Putting aside these problems, it is in this sense that God is said to be a necessary being by those who do not accept the ontological argument, and it is a sense which Kant, in his accusation that the cosmological argument rests upon the ontological, because it is an argument for the existence of a necessary being, entirely fails to grasp. (Kant, believing that nothing happens without a cause, could not suggest that the bare possibility of springing randomly into existence showed that this was not a genuine sense of 'necessary'.) In sum, the objection to Anselm's third argument is that there is a conception of necessary existence, which one might call 'self-subsistence', which is weaker than logically necessary existence, but which is strong enough to rule out having a beginning or an end or an external cause. ${ }^{14}$

One recent defender of OA, E. J. Lowe, does not seem to take notice of this distinction. He expresses the argument as follows.

$\mathbf{N}$ (1) God is, by definition, a maximally great being and thus a being whose existence is necessary rather than merely contingent.

(2) God, so defined, could exist; in other words he does exist in some possible world.

(3) Suppose that $w$ is a possible world in which God, so defined, exists: then it is true, in $w$, at least, that God exists there, and, being God, exists there as a necessary being.

(4) But a necessary being is one which, by definition, exists in every possible world if it exists in any possible world.

\footnotetext{
${ }^{14}$ In Aristotle's Metaphysics Lambda there are two classes of beings necessary in this sense. The ordinary heavenly bodies are not subject to natural generation or decay but they are not self-sufficient in that they owe their being to the prime mover, which is free from generation and decay and wholly self-sufficient. God would be self-sufficient in the strong sense. Lambda, chapter 8 (1073a14 to 1074b14).
} 
(5) Hence, the God who exists as a necessary being in $w$ is a being that exists in every possible world, including this, the actual world. (6) Therefore, God exists in the actual world; he actually exists. ${ }^{15}$ Lowe's form ignores the conditionality of definition, but this can be handled as it is above. The main problem is that he, like Plantinga, assumes that the greatness-making property necessary existence is logically necessary existence, and not the Aristotelian sense of being free from the possibility of generation or decay.

The conflation of these two senses of 'necessary' is explicable in an Aristotelian or medieval context because the view that anything possible is at some time and place actual is often ascribed to Aristotle. It involves equating the space of logical possibility with actual space-time. It is as if 'might have happened to be the case' is conflated with 'might have happened - i.e. come about, or occurred in time.' It is certainly part of the orthodox conception of God that if He exists at all He exists from all eternity and for all eternity, so if the conceivability of His non-existence meant that $\mathrm{He}$ was the sort of thing that might come into existence, His non-existence would be inconceivable. But if we do not make this conflation, the conclusion does not follow.

The issue then seems to be this: can the concept of logically necessary existence be coherently applied to a non-abstract being like God, for if it can the argument is sound and if it cannot, it is not. ${ }^{16}$

\section{A MISTAKEN OBJECTION TO THE ARGUMENT}

There are, broadly, three ways of attacking OA. One is to attack the argument directly, by disputing the truth of a premise or the logic of the argument. The other is to try to show that similar forms of argument give rise to conclusions no-one wants to accept and so to show - or very

${ }^{15}$ E. J. Lowe, 'The Ontological Argument', in The Routledge Companion to the Philosophy of Religion, eds C. Meister and P. Copan (London: Routledge, 2007), pp. 33140. (I have changed only the numbers given to the steps.)

${ }_{16}$ There has been considerable discussion of Gödel's version of the argument; see J. Sobel, Logic and Theism (New York: Cambridge University Press, 2004). As far as I can see, apart from more or less purely formal issues, this raises no new questions. Gödel has one premise which defines God as a being that possesses all and only positive properties, and an axiom that says that necessary existence is a positive property. The parallels between perfection or greatness, and positive properties, and between calling necessary existence a great-making, or perfect-making property and calling it positive are clear enough. So I do not see that new substantive issues arise. 
strongly indicate - that something must be wrong with the argument. Most of the discussion has concerned the first path. The Gaunilo and Caterus strategies are cases of the second. I shall argue in section 9 that these arguments can be countered by claiming that definitional existence (or necessary existence) must supervene (in an intuitive sense of that quasi technical term) on the other properties of the object and cannot be added in an arbitrary way.

There is a third category, similar in some ways to the second, in which there are examples purporting to show that arguments similar to those that prove that maximal greatness is instantiated in some possible world can also be used to show that properties inconsistent with maximal greatness are also instantiated. Plantinga's example ${ }^{17}$ is the property of no-maximality, which is the property of there not being a maximally great entity. This seems to be just as coherent a property as maximal greatness and so to be as good a candidate for being instantiated in some possible world. But if it is, then there is no-maximally great being. Plantinga seems to think that one has to choose between these options, on the basis of faith rather than reason, so to speak.

This does not seem to me to be a strong objection. Maximal greatness is a purported property of first order individuals and no-maximality a property of worlds. This gives priority to maximal greatness, for, in general, world properties depend or supervene on the properties of the objects in them: if maximality has its foot in the door by being a possible property of a first order entity, then no-maximality is excluded.

\section{THE ARGUMENT AND 'A FOOTHOLD IN REALITY’}

In the original version of this paper, cited in footnote 1, I claimed that there is, in fact, a surprising analogy between $\mathbf{J}$ and Anselm's first argument, as expressed in $\mathbf{F}$ above. Both arguments operate by treating as a foothold in reality something which is not such a foothold, and then arguing that if the greatest being conceivable exists in that minor way He must exist in a greater way. In Anselm's case, existence in the mind is wrongly treated as a mode of existence for the thing thought of: for Plantinga, existence in a possible world is similarly confused with a genuine mode of existence. I now think that this interpretation of Plantinga's argument is mistaken.

\footnotetext{
${ }^{17}$ Alvin Plantinga, The Nature of Necessity, pp. 217-21.
} 
In the case of what we have called Anselm's first argument - $\mathbf{F}$ above - the extension from the foothold in reality to full actuality is driven by the demands of 'greatness' - a being existing in an inferior mode cannot be the greatest. In Plantinga's case, however, the move from possible existence to actual is driven by (logically) necessary existence and this works - if it works at all - whether or not you regard existence in a possible world as a genuine form of existence at all: something that exists of logical necessity exists actually, whatever account of possibility one wishes to provide.

It is, however, interesting to note that, if you are a Lewisian realist about possible world, then there is a form of OA using the 'foothold' principle, which is probably sound, given that realism, and given that the notion of a greatest being makes sense.

O. (1) The greatest possible being exists in some possible world (as all possible beings do).

(2) It would be greater to exist in all possible worlds than only in one or some.

Therefore,

(3) The greatest possible being exists in all possible worlds, including the actual world.

The only way that I think a Lewisian might get around this argument is to say that, as transworld existence is only counterpart, the greatness of any real individual is not increased by existing in more worlds. I do not see why this should apply to unchanging necessary beings, however: would a Lewisian Platonist be committed to saying that there was a counterpart number seven in each world, and not the same entity? I shall not pursue this argument here.

\section{LOGICALLY NECESSARY EXISTENCE AND HOW IT WORKS}

The conclusion so far seems to be that the argument is sound if logically necessary existence is the sort of property that it makes sense to attribute to God. The moral that we can draw from Gaunilo-type objections is that this property can only be possessed when it is entailed by the rest of the nature of the object. Necessary existence (or existence by definition) cannot be added simply by stipulation to a list of properties, its presence must be rationalized by those other properties. So, for example, it is 
plausible to hold that numbers, universals and the like are necessary existents because they are abstract entities. A similar principle applies to the Aristotelian, self-sufficiency form of necessary existence. It follows from the nature of the object, namely that it has no matter or parts which could give a mechanism for generation or decay.

Why do abstract entities strike us as plausible candidates for necessary existence? One reason, I think, is that, if one is persuaded to treat them realistically at all, it is difficult to see under what circumstances an abstract object, such as the number seven, for example, could fail to exist. I think that this points to a more general criterion for logically necessary existence, namely that the things taken so to exist are presupposed by a world's being intelligible: they are part of the framework for our finding any world intelligible - with the possible exception of the empty world, though I shall ignore that issue.

So the question is, does this apply to God - is His existence a precondition for a world's being an intelligible place?

At this point, we need to distinguish two kinds of preconditions for intelligibility. One of these is preconditions for the intelligibility of the constitution of the world. The platonic entities come into this category. For example, without numbers, individuation of objects or events would be impossible: without properties or universals there could be no particular way a world is, no states of affairs. The second is explanatory intelligibility: the conditions for making sense of why the world should be, or how it can be, the way it is. It is plausible to claim, I think, that different forms of cosmological argument attempt to show that God is a precondition for the explanatory intelligibility of the worlds of various types. The temporal first cause argument, for example, purports to show that any non-empty world with a temporal dimension must have a cause outside itself; Aquinas's first two ways, that any world with change requires an external cause; teleological arguments, that any world with functional features must be so explained.

So there are three notions of necessary existence in play. These are (i) logically grounded necessity, which is possessed by things whose existence is a precondition of what one might call the descriptive intelligibility of the world; (ii) Aristotelian necessity or the necessity of self sufficiency, which is possessed by anything not subject, in principle, to processes of generation and decay nor dependent on other things; and (iii) explanatorily grounded necessity, according to which something must exist if the world is to make metaphysical sense. God, if He exists, 
certainly possesses the second. Cosmological arguments, if successful, would show that He possesses the third in some form. But the logically necessary existence cannot be attributed to Him on the grounds of His definition, concept or essence, in the way that OA requires.

As a parting flourish, it is interesting to note that this last fact does not mean that God does not meet the condition I gave for being a logically necessary entity, namely that of being a precondition of the descriptive intelligibility of the world. He meets this condition if Aristotle and the neo-Platonists are correct in claiming that the world of logically necessary Platonic entities must be a Divine Intellect, not a collection of self-standing abstract objects, and this Divine Intellect is identical with God. I have defended this neo-Platonic position elsewhere, ${ }^{18}$ but it does not help OA, for that God has this status cannot be proved by the OA strategy, as an argument from 'essence' or 'greatness'; the neo-Platonic strategy is an argument for God's logically necessary existence, not an argument from it.

${ }^{18}$ Howard Robinson, 'Benacerraf's Problem, Abstract Objects and Intellect', in Truth, Reference and Realism, eds Z. Novak and A. Simonyi (Budapest and New York, Central European University Press, 2011), pp. 235-62. 